\title{
Computational investigation of pyrrolidin derivatives as novel GPX4/MDM2-p53 inhibitors using 2D/3D-QSAR, Molecular docking, Molecular dynamics simulations and MM-GBSA free energy
}

\author{
Kamal TABTI ( $\sim$ k.tabti@edu.umi.ac.ma ) \\ Moulay Ismail University: Universite Moulay Ismail \\ Abdelouahid SBAI \\ Moulay Ismail University: Universite Moulay Ismail \\ Larbi ELMCHICHI \\ Moulay Ismail University: Universite Moulay Ismail \\ Hamid MAGHAT \\ Moulay Ismail University: Universite Moulay Ismail \\ Tahar LAKHLIFI \\ Moulay Ismail University: Universite Moulay Ismail \\ Mohammed BOUACHRINE \\ Moulay Ismail University: Universite Moulay Ismail
}

\section{Research Article}

Keywords: MDM2-p53, Spiro [pyrrolidin-3,2-oxindoles], QSAR, Docking molecular, MD simulations, MM-GBSA

Posted Date: January 18th, 2022

DOI: https://doi.org/10.21203/rs.3.rs-1233496/v1

License: @ (i) This work is licensed under a Creative Commons Attribution 4.0 International License. Read Full License 


\section{Abstract}

The p53 is a tumor suppressor protein that adjusts cell cycle and growth arrest as well as genes that restore DNA damage and apoptosis. Murine double minute 2 (MDM2) is a main p53 antagonist. We created a novel QSAR model using a series of highly active spiro [pyrrolidin-3,2-oxindoles] that consisted of 29 compounds that were experimentally validated to inhibit the MDM2-p53 interaction. Three optimal models have been developed CoMFA/E+S, CoMSIA/S+H+A and HQSAR have revealed good statistical results, but the CoMSIA mode only which validates all the external validation tests applied successfully. Based on the CoMSIA/S+H+A model was carefully chosen to design four compounds with values of inhibitory activity greater than the highly active compound in the data set. The Newly designed compounds were docked in the target receptor binding site (ID: 4LWU). The newly designed compound Pred 01 showed the highest affinity with a value of $-9.4 \mathrm{kcal} / \mathrm{mol}$, while compound $\mathrm{N}^{\circ} 04$ which represents the data set and control compound (Nutlin-3) showed binding energies of the order of $-8.8 \mathrm{kcal} / \mathrm{mol}$ and $-8.2 \mathrm{kcal} / \mathrm{mol}$, respectively. In addition, the roles of lipinski and veber were estimated, the results obtained demonstrate that the proposed molecules involve good oral bioavailability and an ability to diffuse through different biological barriers. For in-depth study, The Pred01 / receptor, N04 / receptor and Nutlin-3 / receptor complexes were selected via dynamic simulation analyzes with a simulation time of $100 \mathrm{~ns}$ and, also their free binding energy was examined operating the MM-GBSA approach. The molecular docking results obtained accentuate the crucial residues responsible for the ligand / protein interaction, providing insight into the mode of interaction. The MD simulation analysis confirms the conformational stability of the selected complexes during the MD trajectory, and the fluctuations recorded are insignificant. The results of MM-GBSA reveal that the new compound Pred 01 exhibits the lowest free energy, which confirms the result of molecular docking.

\section{Introduction}

The term ferroptosis was first coined in 2012 to characterize a form of programmed cell death induced by the accumulation of lethal iron-dependent lipid peroxidation [1]. Ferroptosis can be affected by nutritional factors, pharmacological agents, and physiological functions that directy affect these factors. Its may have potential uses in the treatment of cancer, induction of ferroptosis in vivo may have therapeutic value. Multiple pathways can initiate ferroptosis, most of which act directly through the mechanism of using covalent inhibitors to bind glutathione peroxidase 4 (GPX4). It is a uniquely designed selenoprotein that is able to reduce lipid hydroperoxides $(\mathrm{L}-\mathrm{OOH})$ in fatty alcohols $(\mathrm{L}-\mathrm{OH})$ and thus neutralize their toxicity[2, 3].

In recent years, some studies have shown that the p53 protein may be involved in the control of ferroptosis through the accumulation of lipid hydroperoxides or toxic iron [4-6]. The p53 transcription factor is one of the most usually mutated in cancer, and approximately $50 \%$ of human cancers are linked to its mutations or deletions $[7,8]$. In 2015 , the first report of p53 response to ferroptosis was published, the authors discovered that p53 promotes ferroptosis in fibroblasts and some cancer cells that are similar to human breast cancer MCF7[9].

On the other hand, the activity of p53 can be regulated by overexpression of double minute mice 2 (MDM2) and may induce a tendency for tumor growth [10]. Hence, the use of a small molecule inhibitor to reactivate p53 function by disrupting MDM2-p53 interactions is now considered a promising strategy for cancer treatment. BDP (benzodiazepinediones) and nutlines have been identified as the most potent p53-MDM2 interaction abrogators so far Fig. 1[11].

In recent years, the combination of spirooxindole and p pyrrolidine has garnered substantial interest. McConnell et al. developed a series of spirooxindoles fused with 3,2-pyrrolidine, which promotes the formation of functional groups to form $p$-p interactions and hydrogen bond types and provided great properties to these compounds [12]. The mentioned properties of the spirooxindole scaffold fused to 3,2-pyrrolidine reveal the possibility of introducing it synchronously to 
construct a novel dual GPX4 / MDM2 inhibitor. New strategies for designing novel molecules against protein targets are currently in vogue for the development of anticancer treatments.

The QSAR protocol is an process to quantifie a relationship between activity of inhibitors and the structure using mathematical and computer tools for predict the activity biologic of new compounds [13, 14]. In the present research, we performed 2D / 3D QSAR analysis on series of nitroisoxazole derivatives as MDM2-p53 antagonists. In the case of 3D / QSAR modeling, the CoMFA (comparative molecular field analysis) methods and CoMSIA (comparative molecular similarity index analysis) methods were applied to establish the 3D / QSAR model. In addition, a 2D model has been established using the Halogram QSAR method, which is a recent method which. On the contrary 3D-QSAR, avoids the calculation of the molecular descriptors of the compound and it takes a long time therefore this method does not take into account the complexations of the 3D structure and the alignment of molecules to predict their activity. The best model built was based to discover new molecules to disrupt p53-HDM2 interactions. Moreover these proposed molecules, the most active compound and the control compound Nutlin-3 were docked at the MDM2 protein binding site to understand the mode of ligand / protein interaction as well as to identify the amino acids that govern activity. An MD simulation analysis were performed to access the stability of the complexes studied and validate the molecular docking results. The ADME / Tox properties of the modified compounds were also predicted to confirm the biodispobinility of the populated molecules as a drug candidate.

\section{Research Method}

\section{Data set source}

In this research, we selected a database of 29 compounds nitroisoxazole containing spiro [pyrrolidine-oxindole] derivatives from the literature[15]. The basic structure used is replaced by an isoxazole in a small molecule inhibiting GPX4 for the development of new anti-tumor drugs. A fluorine substitution has also been found in the basic structure studied, where it reveals an essential role in improving the efficacy of drugs which has become widespread in recent decades[17, 18]. In particular at the level of the optimization of the molecular properties of a drug and of influencing the selectivity thereof. target by modulating its conformation, permeability, hydrophobicity, metabolism and lipophilicity[19, 29]. In addition, in 2019, eleven fluoride-containing drugs were authorized by the FDA, more than half of

which contain a trifluoromethyl group[20]. This suggested to us that the strategic integration of a trifluoromethyl group can enhance the inhibitory activity of a drug to some level.

The database structures were designed and optimized and again saved in mol2 format utilizing SYBYL X2.0 software[21]. Biological activity data of nitroisoxazole derivatives in these literatures are expressed as Ki (10-6 M), and we have converted them to logarithmic pki (-Log ki). The structures and activity (pKi) used in this work for were collected in Table 1. The 29 compounds were haphazardly divided into 23 compounds for the training set and 6 compounds for the test set in order to facilitate the 3D-QSAR analysis[22]. 
Table 1

Chemical structures and inhibitory activities of nitroisoxazole containing spiro [pyrrolidine-oxindole] derivatives

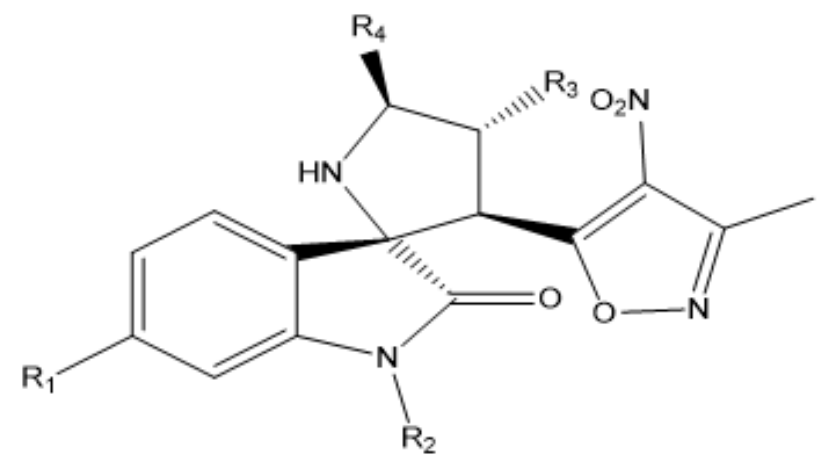

\begin{tabular}{|c|c|c|c|c|c|c|c|c|c|c|c|c|}
\hline \multicolumn{2}{|c|}{$\begin{array}{l}\text { Compound } \\
\mathrm{N}^{\circ}\end{array}$} & \multirow[t]{2}{*}{$\mathrm{R}_{1}$} & \multirow[t]{2}{*}{$\mathrm{R}_{2}$} & \multirow[t]{2}{*}{$\mathrm{R}_{3}$} & \multirow[t]{2}{*}{ R4 } & \multirow{2}{*}{$\begin{array}{l}\mathrm{pKi}_{\text {exp }} \\
\left(10^{-6} \mathrm{M}\right)\end{array}$} & \multicolumn{2}{|c|}{ CoMFA } & \multicolumn{2}{|c|}{ CoMSIA } & \multicolumn{2}{|c|}{ HQSAR } \\
\hline & & & & & & & $\begin{array}{l}\text { pKi } \\
\text { pred }\end{array}$ & Residu & $\begin{array}{l}\text { pKi } \\
\text { pred }\end{array}$ & Residu & $\begin{array}{l}\text { pKi } \\
\text { pred }\end{array}$ & Residu \\
\hline 1 & Train & $\mathrm{H}$ & $\mathrm{H}$ & $\mathrm{Ph}$ & $\mathrm{CF}_{3}$ & 5.893 & 5.890 & 0.003 & 5.919 & -0.026 & 5.882 & 0.011 \\
\hline 2 & Train & $5-\mathrm{F}$ & $\mathrm{H}$ & $\mathrm{Ph}$ & $\mathrm{CF}_{3}$ & 6.309 & 6.458 & -0.149 & 6.371 & -0.062 & 5.998 & 0.311 \\
\hline 3 & Train & $5-\mathrm{Cl}$ & $\mathrm{H}$ & $\mathrm{Ph}$ & $\mathrm{CF}_{3}$ & 6.167 & 6.138 & 0.029 & 6.124 & 0.043 & 5.998 & 0.169 \\
\hline 4 & Train & $6-\mathrm{Cl}$ & $\mathrm{H}$ & $\mathrm{Ph}$ & $\mathrm{CF}_{3}$ & 6.620 & 6.484 & 0.136 & 6.549 & 0.071 & 5.921 & 0.699 \\
\hline 5 & Train & $5-\mathrm{Br}$ & $\mathrm{H}$ & $\mathrm{Ph}$ & $\mathrm{CF}_{3}$ & 5.991 & 5.990 & 0.001 & 5.981 & 0.01 & 5.998 & -0.007 \\
\hline 6 & Test & $6-\mathrm{Br}$ & $\mathrm{H}$ & $\mathrm{Ph}$ & $\mathrm{CF}_{3}$ & 6.585 & 5.570 & 1.015 & 6.41 & 0.175 & 5.921 & 0.664 \\
\hline 7 & Test & $\begin{array}{l}5- \\
\mathrm{NO}_{2}\end{array}$ & $\mathrm{H}$ & $\mathrm{Ph}$ & $\mathrm{CF}_{3}$ & 5.434 & 5.892 & -0.458 & 5.46 & -0.026 & 5.841 & -0.407 \\
\hline 8 & Train & $\begin{array}{l}5- \\
\mathrm{Me}\end{array}$ & $\mathrm{H}$ & $\mathrm{Ph}$ & $\mathrm{CF}_{3}$ & 5.848 & 5.886 & -0.038 & 5.901 & -0.053 & 5.999 & -0.151 \\
\hline 9 & Train & $\mathrm{H}$ & $\mathrm{H}$ & $3-\mathrm{F}-\mathrm{C}_{6} \mathrm{H}_{4}$ & $\mathrm{CF}_{3}$ & 5.943 & 5.942 & 0.001 & 5.941 & 0.002 & 5.895 & 0.048 \\
\hline 10 & Test & $\mathrm{H}$ & $\mathrm{H}$ & $4-\mathrm{F}-\mathrm{C}_{6} \mathrm{H}_{4}$ & $\mathrm{CF}_{3}$ & 5.987 & 5.597 & 0.39 & 5.824 & 0.163 & 5.79 & 0.197 \\
\hline 11 & Train & $\mathrm{H}$ & $\mathrm{H}$ & $\begin{array}{l}4-\mathrm{Cl}- \\
\mathrm{C}_{6} \mathrm{H}_{4}\end{array}$ & $\mathrm{CF}_{3}$ & 5.558 & 5.543 & 0.015 & 5.534 & 0.024 & 5.79 & -0.232 \\
\hline 12 & Train & $\mathrm{H}$ & $\mathrm{H}$ & $\begin{array}{l}2-\mathrm{Br}- \\
\mathrm{C}_{6} \mathrm{H}_{4}\end{array}$ & $\mathrm{CF}_{3}$ & 5.000 & 5.025 & -0.025 & 4.998 & 0.002 & 4.969 & 0.031 \\
\hline 13 & Test & $\mathrm{H}$ & $\mathrm{H}$ & $\begin{array}{l}3-\mathrm{Br}- \\
\mathrm{C}_{6} \mathrm{H}_{4}\end{array}$ & $\mathrm{CF}_{3}$ & 5.556 & 5.863 & -0.307 & 5.459 & 0.097 & 4.969 & 0.587 \\
\hline 14 & Train & $\mathrm{H}$ & $\mathrm{H}$ & $\begin{array}{l}4-\mathrm{Br}- \\
\mathrm{C}_{6} \mathrm{H}_{4}\end{array}$ & $\mathrm{CF}_{3}$ & 5.528 & 5.502 & 0.026 & 5.523 & 0.005 & 5.79 & -0.262 \\
\hline 15 & Train & $\mathrm{H}$ & $\mathrm{H}$ & $\begin{array}{l}4-\mathrm{NO}_{2}- \\
\mathrm{C}_{6} \mathrm{H}_{4}\end{array}$ & $\mathrm{CF}_{3}$ & 5.171 & 5.165 & 0.006 & 5.213 & -0.042 & 5.606 & -0.435 \\
\hline 16 & Train & $\mathrm{H}$ & $\mathrm{H}$ & $\begin{array}{l}\text { 2-Me- } \\
\mathrm{C}_{6} \mathrm{H}_{4}\end{array}$ & $\mathrm{CF}_{3}$ & 5.000 & 5.09 & -0.09 & 5.047 & -0.047 & 4.969 & 0.031 \\
\hline
\end{tabular}




\begin{tabular}{|c|c|c|c|c|c|c|c|c|c|c|c|c|}
\hline 17 & Test & $\mathrm{H}$ & $\mathrm{H}$ & $\begin{array}{l}\text { 4-Me- } \\
\mathrm{C}_{6} \mathrm{H}_{4}\end{array}$ & $\mathrm{CF}_{3}$ & 5.827 & 5.59 & 0.237 & 6.069 & -0.242 & 5.790 & 0.037 \\
\hline 18 & Train & $\mathrm{H}$ & $\mathrm{H}$ & $\begin{array}{l}2-\mathrm{OMe}- \\
\mathrm{C}_{6} \mathrm{H}_{4}\end{array}$ & $\mathrm{CF}_{3}$ & 5.000 & 5.02 & -0.02 & 5.131 & -0.131 & 4.732 & 0.268 \\
\hline 19 & Train & $\mathrm{H}$ & $\mathrm{H}$ & $\begin{array}{l}\text { 4-iPr- } \\
\mathrm{C}_{6} \mathrm{H}_{4}\end{array}$ & $\mathrm{CF}_{3}$ & 5.646 & 5.663 & -0.017 & 5.694 & -0.048 & 5.69 & -0.044 \\
\hline 20 & Train & $\mathrm{H}$ & $\mathrm{H}$ & $\begin{array}{l}2,5-\mathrm{Cl}_{2}- \\
\mathrm{C}_{6} \mathrm{H}_{3}\end{array}$ & $\mathrm{CF}_{3}$ & 5.000 & 5.017 & -0.017 & 4.967 & 0.033 & 4.996 & 0.004 \\
\hline 21 & Test & $\mathrm{H}$ & $\mathrm{H}$ & $\begin{array}{l}3,4-\mathrm{Cl}_{2^{-}} \\
\mathrm{C} 6 \mathrm{H} 3\end{array}$ & $\mathrm{CF}_{3}$ & 5.627 & 6.03 & -0.403 & 5.294 & 0.333 & 5.717 & -0.09 \\
\hline 22 & Train & $\mathrm{H}$ & $\mathrm{H}$ & $\begin{array}{l}3,4- \\
(\mathrm{OMe})_{2-}^{-} \\
\mathrm{C}_{6} \mathrm{H}_{3}\end{array}$ & $\mathrm{CF}_{3}$ & 5.434 & 5.423 & 0.011 & 5.321 & 0.113 & 5.477 & -0.043 \\
\hline 23 & Train & $\mathrm{H}$ & $\mathrm{H}$ & 2-furyl & $\mathrm{CF}_{3}$ & 5.924 & 5.908 & 0.016 & 5.873 & 0.051 & 5.978 & -0.054 \\
\hline 24 & Train & $\mathrm{H}$ & $\mathrm{H}$ & 2-thienyl & $\mathrm{CF}_{3}$ & 5.866 & 5.857 & 0.009 & 5.908 & -0.042 & 5.978 & -0.112 \\
\hline 25 & Train & $\mathrm{H}$ & $\mathrm{H}$ & $\begin{array}{l}\text { a- } \\
\text { naphthyl }\end{array}$ & $\mathrm{CF}_{3}$ & 5.078 & 4.97 & 0.108 & 4.984 & 0.094 & 5.009 & 0.069 \\
\hline 26 & Train & $\mathrm{H}$ & $\mathrm{Me}$ & $\mathrm{Ph}$ & $\mathrm{CF}_{3}$ & 5.000 & 4.996 & 0.004 & 4.988 & 0.012 & 5.038 & -0.038 \\
\hline 27 & Train & $\mathrm{H}$ & allyl & $\mathrm{Ph}$ & $\mathrm{CF}_{3}$ & 5.000 & 4.979 & 0.021 & 4.994 & 0.006 & 5.281 & -0.281 \\
\hline 28 & Train & $\mathrm{H}$ & Ac & $\mathrm{Ph}$ & $\mathrm{CF}_{3}$ & 5.000 & 4.979 & 0.021 & 4.985 & 0.015 & 4.987 & 0.013 \\
\hline 39 & Train & $\mathrm{H}$ & $\mathrm{H}$ & $\mathrm{Ph}$ & $\mathrm{Ph}$ & 5.199 & 5.252 & -0.053 & 5.23 & -0.031 & 5.980 & -0.781 \\
\hline
\end{tabular}

\section{Minimization and alignment of molecular structure}

The structures of the selected compounds were minimized using the conjugate gradient under the standard Tripos Field force field implanted in SYBYL-X2.0 [23] with partial atomic charges of Gasteiger-Hückel by the method of Powell with a convergence criterion of $0.05 \mathrm{Kcal} / \mathrm{mol}$. The maximum iterations number is 10.000 . Molecular alignment is an essential stage in 3D-QSAR for associated the orientation of molecules in 3D space. The highest activity compound $\mathrm{N}^{\circ} 04$ was used as a template for alignment. The result of the structural alignment of all inhibitor molecules and the template compound structure is presented in Fig. 2.

\section{Construction 3D-QSAR models}

3D-QSAR study included the usage of CoMFA and CoMSIA, They are based on the idea that a compound of similar structure interacting with the receptor site in the same mode implies that the molecular fields involving them must also be similar, which shows that the biological activity of the compounds is intimately connected to the molecular field that neighborhoods them. Using the Lenard-Jones function to compute the steric field (S), as well as the Coulomb function to determine the electrostatic field (E), the CoMFA model focuses primarily on van der Waals interactions[24].

Since most of interactions are very complex, and sometimes the steric field and the electrostatic field are insufficient to build the model. For this reason, we had to integrate the CoMSIA method[25]. The essential principle of the CoMSIA 
model is similar to CoMFA, with the addition of a hydrophobic field $(H)$, a hydrogen bond donor field (D) and a hydrogen bond acceptor field (A). The grid 3D used the spacing grid 2.0 $\mathrm{A}$ with the three Cartesian directions. The Gaussian function is used to calculate the energy of the field molecular. The attenuation factor was set at 0.3.

\section{PLS method}

The relation between the activity and the descriptors CoMFA, CoMSIA and HQSAR was quantified by the method of the partial least squares (PLS) integrated in SYBYL X2.0 [26]. We carried out a Leave-one-out (LOO) to select the best value of validation coefficient cross $\mathrm{Q}^{2}$ and the best principal component number (NOC). The value of the correlation coefficient $\left(R^{2}\right)$, the value $F$, the standard deviation of estimate (SEE) and the percentage of contribution were selected by non-validation. The 3D-QSAR model is predictive and reliable if $\mathrm{Q}^{2}>0.5, r^{2}>0.6$, the SEE value should be as little as possible and the $F$ value should be as large as possible [27].

\section{Construction HQSAR model}

The HQSAR method is a novel two-dimensional QSAR method that provides an unequaled advantage in molecular design. HQSAR can certainly display where optimization is required, as well as which groups of atoms contribute positively or negatively to molecular activity and find the appropriate structural substitutions in molecule design. The fragment parameters and fragment size were modified during the optimization technique of the HQSAR model. The fragmentation parameter defines how the hologram's topology information is mapped. The atomic number (A) indicates the type of the atom; The type of bond $(B)$ indicates the chemical bond formed between atoms; Atomic connection (C) distinguishes the chemical bond in the fragment; hydrogen atom $(\mathrm{H})$ represents hydrogen atom of the fragment; Chirality (Ch) represents stereochemical information about atomic chirality; hydrogen bond donor / acceptor (DA) signifies the hydrogen bond donor or acceptor of the fragment. In this method we chosen 12 holographic lengths $(53,59,61,71,83,97,151,199,257,307,353$ and 401) to build the different HQSAR models[28].

\section{Validation of the CoMFA, CoMSIA and HQSAR models}

The selected 3D-QSAR and HQSAR models must also be validated by external validation by using the test set reserved, The external validation was carried out according to Golbraikh-Tropsha criteria and using Roy metrics [30-32]. The conditions that the 3D-QSAR models and the HQSAR model must meet certain conditions for a more reliable external predictive capacityare as follows:

$-Q^{2}>0.5, R^{2}>0.6,\left(r^{2}-r_{0}^{2}\right) / r^{2}<1,\left(r^{2}-r_{0}^{\prime 2}\right) / r^{2}<0.1,0.85 \leq k^{\prime} \leq 1.15,0.85 \leq k \leq 1.15$

$$
\begin{gathered}
R^{2}=1-\frac{\sum\left(y_{i}-\hat{\mathrm{y}}_{i}\right)}{\sum\left(y_{i}-\overline{\mathrm{y}}_{i}\right) \square} \\
Q^{2}=1-\frac{\sum\left(y_{i}-y_{i}^{\prime}\right)}{\sum\left(y_{i}-y_{\text {mean }}\right)}
\end{gathered}
$$

Where:

$\mathrm{k}$ and $\mathrm{k}$ are respectively the slope of the predicted values to those observed and the observed values to those predicted for the test set with zero intercepts/

$-\Delta r_{m}^{2}<0.2, \Delta r_{m}^{\prime}<0.2, \widehat{r}_{m}^{2}>0.5$, in Roy's criteria.

$$
r_{m}^{2}=r \square\left(1+\sqrt{\left(r^{2}-r_{0}^{2}\right)}\right.
$$




$$
\left.r_{m}^{2}=r\right]\left(1+\sqrt{\left(r^{2}-r_{0}^{2}\right)}\right.
$$

Where

- $-r^{2}$ is the square correlation coefficient of the predicted and observed activity values of the test phase.

- $-r^{2}{ }_{0}$ and $r^{\prime 2}{ }_{0}$ are respectively the coefficients for determining predicted values and those observed and the observed values and those predicted for the test set with zero interception.

\section{Molecular docking study}

In this work, molecular docking was used to understand the mechanism of interactions between nitroisoxazole derivatives and the chosen receptor code was obtained from the RCSB protein database (https : //www.rcsb.org/) PDB: 4LWU. The AutoDock program performed all molecular docking steps[32]. Within a week of removing all water molecules. The polar hydrogen atoms and Gasteiger charges were added to the receptor protein chain. A grid box spacing of $0.708 \AA$ was taken, with a number point in $x, y$, and z-dimensions of $-11.639,21.472$, and -4.528 , respectively. Molecular docking generated nine conformations based on docking affinity, the conformation with the lowest binding energy was then selected.

Furthermore, re-docking of X-ray bound ligand (20U) into their own active site was executed to validate the accuracy of the molecular docking protocol. A molecular docking protocol is reliable if the root mean square deviation (RMSD) is less than $2 \AA[33]$.

\section{Dynamic molecular analysis}

The Desmond program, a 2005 explicit solvent MD package with the OPLS fixed force field, was used to run MD simulations on the best docked ligand-protein complexes[34]. To simulate the system, an orthorhombic box with periodic boundary conditions was utilized as the solvent and a preset SPC (Simple Point Charge) water model as the solvent. An electrically neutral simulation system was constructed of $0.15 \mathrm{M} \mathrm{NaCl}$ was developed. Using the NoseHoover thermostat algorithm and the Martyna-Tobias-Klein Barostat method, we stabilized the temperature at $300 \mathrm{~K}$ and the pressure at $1 \mathrm{~atm}$ throughout the simulation[36-38]. For $100 \mathrm{~ns}$, the simulation was run under TNP conditions, and the trajectory information was acquired using the Berendsen thermostat and barostat methods throughout the remaining 2 ps[38].

\section{Simulation binding free energy analysis}

In order to calculate binding free energies of ligand-protein complexes, molecular mechanics and generalized Born surface area (MM-GBSA) were operated. A simulation with the VSGB solvation model and the OPLS3e force field was run with a 100-step sample size on frames 0-501 to estimate the Prime MM-GBSA binding free energy. For Prime MMGBSA's free binding energy $(\mathrm{kcal} / \mathrm{mol})$, the additivity principle was employed in which each component's separate energy modules were combined to estimate the binding free energy of the protein and ligand.

\section{Lipinski rule}

The molecular properties of a compound influence pharmacodynamics and its pharmacokinetics. Hence optimize their absorption, distribution, metabolism and excretion (ADME) in the human body as a drug. Lipinski's rule validation demonstrate good oral bioavailability and a balance between the aqueous solubility of a compound and its ability to passively diffuse through different biological barriers. 
furthermore, Veber's rule indicates that molecular flexibility and polar surface area (PSA) are crucial factors of oral bioavailability[39]. This molecular flexibility governed by the number of rotating bonds. Reduced molecular flexibility and low PSA are important predictors of good oral bioavailability that molecular flexibility determined by the number of rotating bonds. The reduction in molecular flexibility and the low PSA are important predictors of good oral bioavailability[40].

\section{Results And Analysis}

\section{D-QSAR statistical results}

A CoMFA analysis was generated with static and electrostatic fields and, 31 possible combinations of five descriptors for the CoMSIA analysis, as the dependence on the five CoMSIA descriptors results in a decrease in the significance of the model[41]. We selected the models with values $\mathrm{Q}^{2}$ and $\mathrm{R}^{2}$ were respectively greater than 0.5 and 0.6 Table 2 .

Table 2

Statistical parameters of CoMSIA models with different combinations of molecular fields.

\begin{tabular}{|c|c|c|c|c|c|c|c|c|c|c|c|c|}
\hline \multirow[t]{2}{*}{ Model } & & \multicolumn{4}{|c|}{ No validation } & \multicolumn{2}{|c|}{$\begin{array}{l}\text { Leave-One- } \\
\text { Out (LOO) }\end{array}$} & \multicolumn{5}{|c|}{ Field distribution (\%) } \\
\hline & & $\mathrm{R}^{2}$ & SEE & $F$ & $\mathbf{R}_{\text {pred }}^{2}$ & $\mathrm{Q}^{2}$ & NOC & $S$ & $E$ & $\mathrm{H}$ & D & A \\
\hline CoMFA & $E+S$ & 0.987 & 0.066 & 208.357 & 0.553 & 0.553 & 6 & 44.2 & 55.8 & - & - & - \\
\hline \multirow[t]{7}{*}{ CoMSIA } & $\begin{array}{l}\mathrm{H}+ \\
\mathrm{A}\end{array}$ & 0.988 & 0.064 & 223.422 & 0,559 & 0.533 & 5 & - & - & 39.6 & - & 60.4 \\
\hline & $\begin{array}{l}\mathrm{S}+ \\
\mathrm{H}+ \\
\mathrm{A}\end{array}$ & 0.988 & 0.065 & 217.030 & 0,794 & 0.563 & 5 & 15.8 & - & 31.2 & & 53 \\
\hline & $\begin{array}{l}\mathrm{H}+ \\
\mathrm{D}+ \\
\mathrm{A}\end{array}$ & 0.982 & 0.079 & 143.318 & 0,945 & 0.521 & 5 & - & - & 28.5 & 25.9 & 53.0 \\
\hline & $\begin{array}{l}\mathrm{S}+ \\
\mathrm{E}+ \\
\mathrm{H}+ \\
\mathrm{A}\end{array}$ & 0.990 & 0.06 & 256.781 & 0,511 & 0.511 & 5 & 11.5 & 29.6 & 21.4 & - & 37.5 \\
\hline & $\begin{array}{l}\mathrm{S}+ \\
\mathrm{E}+ \\
\mathrm{H}+ \\
\mathrm{D}\end{array}$ & 0.981 & 0.081 & 136.993 & 0,994 & 0.502 & 6 & 12.8 & 37.9 & 24 & 25.4 & - \\
\hline & $\begin{array}{l}\mathrm{S}+ \\
\mathrm{H}+ \\
\mathrm{D}+ \\
\mathrm{A}\end{array}$ & 0.982 & 0.078 & 148.929 & 0,898 & 0.541 & 5 & 11.8 & - & 23.4 & 23.4 & 41.4 \\
\hline & $\begin{array}{l}\mathrm{S}+ \\
\mathrm{E}+ \\
\mathrm{H}+ \\
\mathrm{D}+ \\
\mathrm{A}\end{array}$ & 0.986 & 0.070 & 183.314 & 0,855 & 0.517 & 5 & 9.4 & 23.3 & 17.3 & 19 & 31 \\
\hline
\end{tabular}

In the case of the CoMFA model, the values for the optimal number of components (ONC), $\mathrm{Q}^{2}, \mathrm{R}^{2}, \mathrm{~F}$ and SEE were obtained, at $6,0.553,0.987,208.357$ and 0.066 , respectively. The contributions of steric and electrostatic fields to the CoMFA model were 44.2 and $55.8 \%$, respectively. Among the seven CoMSIA models, the best model is the CoMSIA / 
$\mathrm{S}+\mathrm{H}+\mathrm{A}$ model with steric, hydrophobic and acceptor hydrogen bond fields, the $\mathrm{Q}^{2}, \mathrm{R}^{2}, \mathrm{~F}$ and $\mathrm{SEE}$ values were determined at $0.563,0.988,217.030$ and 0.065 , respectively. The contributions of steric and hydrophobic fields and acceptor hydrogen bond to the CoMFA model were 15.8, 31.2 and 53\%, respectively, signaling that the acceptor hydrogen bond field created the higher contribution to the binding affinity.

The CoMFA and CoMSIA models have been validated by the reserved test set. The $\mathrm{R}^{2}$ pred values of CoMFA and CoMSIA were calculated to be 0.553 and 0.794 , respectively. Which shows the strong predictability of the CoMSIA model compared to the CoMFA model.

\section{HQSAR statistical results}

The construction of the HQSAR model was adopted by three factors, containing the fragment size, the fragment distinction and hologram length. The statistical parameters of the established HQSAR models are presented in Table 34 , the parameters $\mathrm{R}^{2}, \mathrm{Q}^{2}$ and SEE were used to display the validity of the models.

Table 3

HQSAR analysis of various fragment distinctions use up fragment size (4 - 7)

\begin{tabular}{|llllllll|}
\hline Model & Fragment & $\mathbf{Q}^{2}$ & SEE $_{\mathrm{CV}}$ & $\mathrm{R}^{2}$ & SEE & Best HL & NOC \\
\hline 13 & B +H & 0.660 & 0.323 & 0.796 & 0.251 & 257 & 4 \\
\hline 14 & $\mathrm{~B}+\mathrm{Ch}$ & 0.650 & 0.331 & 0.709 & 0.211 & 257 & 4 \\
\hline 35 & $\mathrm{~B}+\mathrm{DA}$ & 0.591 & 0.354 & 0.835 & 0.225 & 257 & 4 \\
\hline 36 & $\mathrm{~B}+\mathrm{H}+\mathrm{Ch}$ & 0.660 & 0.323 & 0.796 & 0.251 & 257 & 4 \\
\hline 37 & $\mathrm{~B}+\mathrm{Ch}+\mathrm{DA}$ & 0.591 & 0.354 & 0.835 & 0.225 & 257 & 4 \\
\hline 45 & $\mathrm{~A}+\mathrm{B}+\mathrm{H}+\mathrm{Ch}$ & 0.494 & 0.418 & 0.925 & 0.161 & 199 & 6 \\
\hline 48 & $\mathrm{~A}+\mathrm{C}+\mathrm{H}+\mathrm{Ch}$ & 0.508 & 0.388 & 0.877 & 0.195 & 353 & 4 \\
\hline 54 & $\mathrm{~B}+\mathrm{H}+\mathrm{Ch}+\mathrm{DA}$ & 0.591 & 0.354 & 0.835 & 0.225 & 257 & 4 \\
\hline 57 & $\mathrm{~A}+\mathrm{B}+\mathrm{C}+\mathrm{H}+\mathrm{Ch}$ & 0.602 & 0.371 & 0.962 & 0.115 & 97 & 6 \\
\hline
\end{tabular}

The most excellent hologram model was generated using a histogram length of 257 having four optimal components. The descriptors used to create the model were $\mathrm{B}$ (bonds) and $\mathrm{H}$ (hydrogen atom), the addition of descriptor Ch (chirality) on this model does not add any advantage in terms of the statistical parameters. The best model generated had a $\mathrm{Q}^{2}$ cross-validation coefficient value of 0.66 and a non-validation $\mathrm{R}^{2}$ value of 0.796 with a standard error of 0.323. and the fragment size of $4-7$. 
Table 4

Statistical parameters of HQSAR model using the fragments $\mathrm{B}+\mathrm{H}$ with different fragment sizes.

\begin{tabular}{|llllllll|}
\hline Model & Fragment & $\mathrm{Q}^{2}$ & SEE cv & $\mathbf{R}^{2}$ & SEE & Best LH & NOC \\
\hline $1-4$ & $\mathrm{~B}+\mathrm{H}$ & 0.284 & 0.497 & 0.722 & 0.310 & 353 & 6 \\
\hline $2-5$ & $\mathrm{~B}+\mathrm{H}$ & 0.336 & 0.465 & 0.803 & 0.253 & 199 & 5 \\
\hline $3-6$ & $\mathrm{~B}+\mathrm{H}$ & 0.618 & 0.352 & 0.848 & 0.222 & 257 & 5 \\
\hline $4-7$ & $\mathrm{~B}+\mathrm{H}$ & 0.660 & 0.323 & 0.796 & 0.251 & 257 & 4 \\
\hline $5-8$ & $\mathrm{~B}+\mathrm{H}$ & 0.633 & 0.327 & 0.759 & 0.265 & 199 & 3 \\
\hline $6-9$ & $\mathrm{~B}+\mathrm{H}$ & 0.600 & 0.351 & 0.820 & 0.235 & 199 & 4 \\
\hline $7-10$ & $\mathrm{~B}+\mathrm{H}$ & 0.523 & 0.372 & 0.762 & 0.263 & 307 & 3 \\
\hline $8-11$ & $\mathrm{~B}+\mathrm{H}$ & 0.585 & 0.347 & 0.783 & 0.251 & 97 & 3 \\
\hline $9-12$ & $\mathrm{~B}+\mathrm{H}$ & 0.580 & 0.349 & 0.782 & 0.252 & 257 & 3 \\
\hline $10-13$ & $\mathrm{~B}+\mathrm{H}$ & 0.587 & 0.347 & 0.795 & 0.244 & 97 & 3 \\
\hline $11-14$ & $\mathrm{~B}+\mathrm{H}$ & 0.543 & 0.397 & 0.969 & 0.103 & 257 & 6 \\
\hline $12-15$ & $\mathrm{~B}+\mathrm{H}$ & 0.606 & 0.348 & 0.925 & 0.151 & 267 & 4 \\
\hline $13-16$ & $\mathrm{~B}+\mathrm{H}$ & 0.648 & 0.349 & 0.973 & 0.097 & 199 & 6 \\
\hline
\end{tabular}

\section{Validation of QSAR models}

The predictive capacities of the QSAR models were validated externally using the six molecules reserved for the set of tests [29]. As it was mentioned after that the parameters $\mathrm{Q}^{2}$ and $\mathrm{R}^{2}$, obtained from internal validation, are necessary but insufficient to confirm the stability and the predictive capacity of the models.

The results of the external validation are listed in Table 5. The best QSAR models for the test set gave the $R^{2}$ pred, $r^{2}$, $\mathrm{r}_{\mathrm{m}}{ }_{\mathrm{m}}, \mathrm{r}_{\mathrm{m}}{ }_{\mathrm{m}}$ and $\Delta \mathrm{r}_{\mathrm{m}}^{2}$ values of $0.555,0.554,0.215,0.385$ and -0.337 (CoMFA), 0.794, 0.795, 0.574, 0.634 and -0.320 (CoMSIA), 0.559, 0.286, 0.381, 0.470 and -0.178 (HQSAR) and the slope regression slope values $k$ and $k^{\prime}$ of 1.011 and 0.981 (CoMFA), 1.014 and 0.985 (CoMSIA), and 1.052 and 0.949 (HQSAR) for MDM2-p53 activity inhibitory, respectively. The values of the parameters $r^{2}{ }_{0}$ and $r^{2}{ }_{0}$ are 0.975 and 0.924 (CoMFA); 0.962 and 0.959 (CoMSIA), and 0.500 and 0.458 (HQSAR) for inhibitory activity, respectively, were used to calculate the relationships $\left(r^{2}-r^{2}{ }_{0}\right) / r^{2}$ and $\left(r^{2}-r_{o}^{2}\right) / r^{2}$ values were obtained from $-0,765$ and -0.673 (CoMFA), -0.211 and -0.204 (CoMSIA), and 0.106 and 0.182 (HQSAR). 
Table 5

Golbraikh and Tropsha test results

\begin{tabular}{|c|c|c|c|c|}
\hline \multirow[t]{2}{*}{ Statistical Parameters } & & \multicolumn{2}{|c|}{ 3D-QSAR } & \multirow{2}{*}{$\begin{array}{l}\text { 2D-QSAR } \\
\text { HQSAR }\end{array}$} \\
\hline & & CoMFA & COMSIA SHA & \\
\hline \multirow[t]{7}{*}{ Tropsha and Golbraikh's criteria } & $r_{0}^{2}$ & 0.975 & 0,962 & 0.500 \\
\hline & $r_{0}^{\prime}{ }^{2}$ & 0.924 & 0,956 & 0.458 \\
\hline & $\mathrm{R}^{2}$ pred & 0.555 & 0,794 & 0.559 \\
\hline & $\mathrm{k}$ & 1,011 & 1,014 & 1,052 \\
\hline & $\left(R^{2}+R_{0}^{2}\right) / R^{2}$ & $-0,765$ & $-0,211$ & 0,106 \\
\hline & $k^{\prime}$ & 0,981 & 0,985 & 0,949 \\
\hline & $\left(R^{2}+R_{0}^{\prime 2}\right) / R^{2}$ & $-0,673$ & $-0,204$ & 0,181 \\
\hline \multirow[t]{5}{*}{ Roy's criteria } & $\mathrm{r}_{\mathrm{m}}{ }^{2}$ & 0.554 & 0,795 & 0.286 \\
\hline & $r_{m}^{\prime}{ }^{2}$ & 0.215 & 0,574 & 0,381 \\
\hline & $\bar{r} \square_{\mathrm{m}}$ & 0.385 & 0,634 & 0,470 \\
\hline & $\Delta r_{\mathrm{m}}^{2}$ & $-0,337$ & $-0,320$ & $-0,178$ \\
\hline & $\Delta \mathrm{r}_{0}^{2}$ & 0,051 & 0.006 & 0,042 \\
\hline
\end{tabular}

Considering the values of the performance parameters provided by the external validation (Table 5), it is obvious that among the three models generated, only the CoMSIA model respected all the criteria of Tropsha and Glorbaikh, and the metrics of Roy. these results validated the predictive power of the CoMSIA / S+H+A model to estimate the biological activities of new compounds.

The correlation plots between the experimental pki and predicted pki and the residuals of the CoMFA and CoMSIA and HQSAR models are displayed in Fig. 3a, 3b and 3c, respectively.

\section{Visualization contour carts CoMFA and CoMSIA}

The ability to visualize the results as three-dimensional contour plots is an intriguing feature of CoMFA and CoMSIA modeling. The contour maps were created by multiplying the coefficients and standard deviations associated with each CoMFA or CoMSIA column by a scalar product. The resulting maps depict regions with scaled coefficients greater than or equal to $80 \%$ (favored/unfavored). They will give us with sufficient information about the regions that are favorable or unfavorable for the compounds' activity, allowing us to tweak and strengthen the inhibitors previously reported.

The steric and electrostatic fields for CoMFA analysis are illustrated by contour plots on the most active compound $\mathrm{N}^{\circ} 04$ as seen in Fig. 4. In the case the steric field CoMFA, green contours indicate regions where bulky groups improve biological activity, while yellow contour indicate regions where bulky groups decrease activity. The presence of two significant zones of green contours around the chlorine atom of $\mathrm{R}_{1}$ substitution and the $\mathrm{CF}_{3}$ group of $\mathrm{R}_{3}$ substitution indicates that the substituents at these locations have favorable steric interactions. A small green contour between the 
para and ortho phenyl ring positions of the $\mathrm{R}_{4}$ substitution suggests that the bulky substituents will rise proportionally biological activities. Three yellow polyhedrons concentrated around the meta position of the $\mathrm{R}_{3}$ substitution phenyl ring suggest that less bulky substituents in the position will improve biological activity (Fig. 4a).

The Fig. $4 \mathrm{~b}$ was the contour map of the electrostatic field, the electronegative and electropositive regions were represented by blue and red contours, respectively. Red and blue contours indicate regions where bulky groups improve biological activity, while yellow contour indicate regions where bulky groups decrease activity. Three red contours around the $\mathrm{CF}_{3}$ group, as well as the $\mathrm{NO}_{2}$ and methyl of the isoxazole group, signal that these positions are appropriate for electronegative groups to considerably increase biological activity (Fig. 4b). Two small blue contour regions between pyrrole and isoxazole and near the core of $\mathrm{R}_{3}$ substituent phenyl indicate positively charged substituents may improve activity.

In the case of the CoMSIA model, the steric, hydrophobic, hydrogen bond acceptor contours are presented in Fig. 5. In the steric field, green contours indicate regions where bulky groups improve biological activity, while yellow contour indicate regions where bulky groups decrease activity. In the map of steric contours of CoMSIA, we noticed two large contours one near the $\mathrm{CF}_{3}$ group of $\mathrm{R}_{4}$ substitution, and the other covers the ortho and meta position of $\mathrm{R}_{3}$ substitution phenyl which indicates that a bulky substitution is required in this region. Furthermore, we could also see two large yellow contours covering the two faces of the isoxazole ring showing that the substitution in this position is unfavorable to the increase in activity Fig. 5a. In the hydrophobic field, the yellow contour indicates the regions where the hydrophobic areas are favorable, while the gray contour indicate the regions where the hydrophile regions are favorable. the hydrophobic grey contours covering the $\mathrm{R}_{4}$ substitution $\mathrm{CF}_{3}$ group, the phenyl para position of the $\mathrm{R}_{3}$ substitution and also $\mathrm{NO}_{2}$ group, suggest that the substitution of hydrophilic groups in these positions could enhance biological activity. while yellow outlines localize near the chlorine atom of group $\mathrm{R}_{1}$, and around oxindole show that the substitution of the hydrophobic groups could enhance the activity Fig. $5 \mathrm{~b}$.

The hydrogen bonds acceptor field (A) plays a major role in the bioactivity compared to the steric and hydrophobic fields (percentage contribution 53\%). The cyan colored contour and the purple colored contour denote the hydrogen bond acceptor favorable and unfavorable region. As shown in Fig. $5 \mathrm{c}$, a large cyan contour near the $\mathrm{NO}_{2} \mathrm{group}$ indicates that the hydrogen bond acceptor group at this position suitable for activity. The unfavorable hydrogen bond acceptor red contour was noticed near the ring of the phenyl ring, indicating that the hydrogen bond acceptor group is not favorable at this position.

\section{Hologram QSAR Atomic Contribution Plot Interpretation}

On the most active compound $\mathrm{N}^{\circ} 04$, as well as the least active compound $\mathrm{N}^{\circ} 20$, an atomic contribution graph generated by the HQSAR model is shown Fig. 6. The different colors indicate the degree which each atom contributes to the total biological activity. The negative contributions are illustrated by the red, red-orange, and orange patterns,

while the positive contributions are displayed by the yellow, green, and blue-green patterns. Grey colors have been used to indicate intermediate contributions. The most common substructure has been indicated in cyan. The appearance of red or orange phenyl hydrogen indicates that it contributed negatively to the activity. The hydrogen atoms of isoxazole's methyl group were whitish, indicating an intermediate contribution.

\section{Designed molecular docking results and analysis}

The results of established 3D-QSAR models were used for the design of new potent inhibitors, as shown in the Table 6. Compound $\mathrm{N}^{\circ} \mathrm{O} 4$ exhibited the highest activity and was taken as a template to design new compounds. In the phenyl ring at the $\mathrm{R}_{3}$ substitution, there was the favorable steric contour between the para and meta position, suggesting that 
bulky substitutions increased biological activity. As a result, cyclohyptane was introduced at this position, and the Pred01 compounds were designed.

Table 6 Structure, predicted pKi and affinity of newly designed compounds

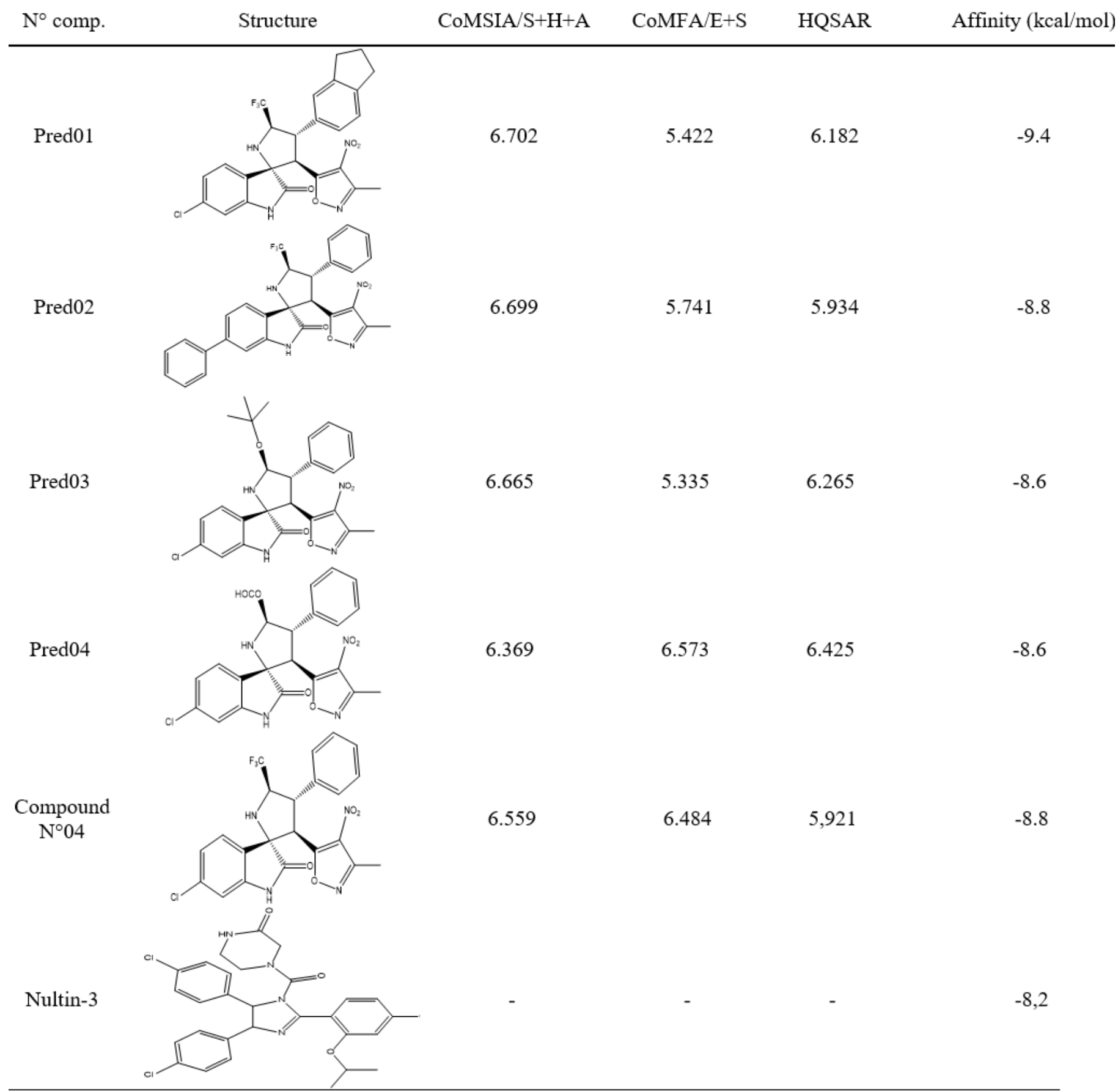

The four designed compounds, the most potent inhibitor ( $\left.\mathrm{N}^{\circ} 04\right)$, as well as the control were docked in the binding site of protein, for the purpose of detecting the key amino acids in the biological activity studied, as well as to acquire indepth insight into crucial interaction modes. We selected the conformation with the highest affinity score value among nine output conformations. According to the docking result, the newly designed compound Pred01 had the highest binding affinity $-9.4 \mathrm{kcal} / \mathrm{mol}$, while compound $\mathrm{N}^{\circ} 04$ and Nutlin showed an affinity of $-8.4 \mathrm{kcal} / \mathrm{mol}$ and -9.2 respectively Table 6. The amino acid His92 is in a suitable position to be involved in the formation of hydrogen bond

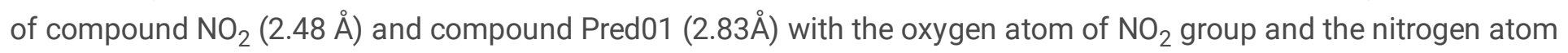
of isoxazole respectively. These observations are precisely in agreement with the contour maps of the $\mathrm{H}$-binding 
acceptor in the CoMSIA odels. In addition, the compound Pred03 form a hydrogen bond with the same His92 residue on distance $2.56 \AA$. These results indicating this amino acid plays an essential role in controlling activity (Fig. 7). Thus, these residues may be critical indications for rational design to find out more potent MDM2-p53 inhibitors.

The docking methodology was validated by the redocking technique by redecking the co-crystallized ligand, then calculating the RMSD between the reference co-crystalline and the re-docked co-crystallized as shown in Fig. 8 . The result of the docking showed that the docking of the co-crystallized ligand shows an RMSD value equivalent to $0.87 \AA$, indicates that the methodology is accurate in predicting the binding affinity for ligands.

\section{Lipinski rules and veber parametrs}

The lipinski rules are widely used to assess drug-like compounds. According to these rules, compounds that do not meet at least two of the following criteria are very likely to have problems with absorption or oral permeability[42]. The Veber and lipinski properties of the newly designed compounds are collected in Table 7.

Table 7

lipinski and veber rules for newly designed compounds

\begin{tabular}{|c|c|c|c|c|c|c|c|c|}
\hline \multirow[t]{2}{*}{ Comp. } & \multicolumn{5}{|c|}{ Lipinski rule } & \multicolumn{2}{|c|}{ Veber rules } & \multirow[t]{2}{*}{ Synthetic accessibility } \\
\hline & MW & NBA & NBD & $\mathrm{Log}^{\mathrm{L}}$ & $\begin{array}{l}\text { Molar } \\
\text { Refractivity }\end{array}$ & $\begin{array}{l}\text { Nrot } \\
\text { Bond }\end{array}$ & PSA & \\
\hline Pred01 & 532.90 & 9 & 2 & 6.01 & 136.10 & 4 & 112.98 & 5.33 \\
\hline Pred 02 & 534.49 & 9 & 2 & 6.53 & 143.90 & 5 & 112.98 & 5.44 \\
\hline Pred 03 & 496.94 & 7 & 2 & 4.47 & 138.83 & 5 & 122.21 & 5.44 \\
\hline Pred 04 & 468.85 & 8 & 2 & 2.82 & 124.96 & 5 & 139.28 & 5.01 \\
\hline $\mathrm{N}^{\circ} 04$ & 492.84 & 9 & 2 & 5.52 & 123.47 & 4 & 112.98 & 5.04 \\
\hline
\end{tabular}

According to Table 7, the most soluble compound in aquatic and lipid solutions is Pred 01, followed by Pred03, $\mathrm{N}^{\circ} 04$, Pred01, and Pred02. Giving to Lipinski's rules, these compounds should have no difficulty with oral bioavailability. We note that all compounds have PSA and Nrot Bond values of less than $140 \mathrm{~A}^{2}$ and 10 respectively, indicating that they are well predicted for oral bioavailability and membrane transport. We can convince these compounds to comply with Veber's rule. As shown in Table 7, the synthetic accessibility values of the new compounds are located within a range closest to the representative molecule of the dataset $\mathrm{N}^{\circ} 04$ and can be considered encouraging.

\section{Molecular dynamics analysis}

In this part, we have selected three complex $\mathrm{N}^{\circ} 04$ /receptor, Nutlin-3/receptor and Pred 01/receptor. For a study molecular dynamics simulations were performed in $100 \mathrm{~ns}$ to assess conformational stability very much closer to physiological environmental conditions. The RMSD trajectories of free protein and ligand-protein complexes were used to assess the stability of the selected systems as were illustrated in Fig. 10.

RMSD values of free protein alpha carbons showed changes during the first simulation of $70 \mathrm{~ns}$, then became stable after $70 \mathrm{~ns}$ for all three systems. For the ligand $\mathrm{N}^{\circ} 04$, Nutlin-3 and Pred 01, there were fluctuations at the start, then all the complexes gradually reached equilibrium at $56 \mathrm{~ns}, 58 \mathrm{~ns}$ and $75 \mathrm{~ns}$ of simulation respectively. During the last $35 \mathrm{~ns}$ of simulation, the RMSD values of compound Pred 01 , Nutlin-3 and compound $N^{\circ} 04$ varied around $1.6 \AA$, $2.4 \AA$ and $4.2 \AA$ respectively, indicating that compound Pred 01 could form a more stable complex with the target protein binding site Fig. 9. 
The evolution of RMSF for the three complexes, indicating the local changes in the protein chains, generally the three complexes fluctuate weakly such that does not exceed $3 \AA$, but the complex relating to compound Pred 01 fluctuates more weakly than the others and does not exceed $2 \AA$ Fig. 10.

The interactions of protein/ligand and the graphs of contacts were monitored throughout the simulation are also illustrated in Fig. 11. During the MD simulation equilibrium steps the protein-ligand interactions were evaluated to identify the crucial residues involved in the interaction for the three ligands. For compound $\mathrm{N}^{\circ} 04$, the most stable interactions were hydrophobic conctates with His92, Leu50, lle95 and Ile 57 accounting for $30,28,26,17 \%$ of the whole Simulation Trajectory, respectively. Other hydrogen bond interactions formed with His92 and GIn55 were also observed, His92 formed a hydrogen bond with the nitrogen dioxide group, with percentages of 12 and $5 \%$ respectively, indicating the hydrophobic interaction formed with these residues played an important role in the inhibitory activity interacting with the protein.

In addition, the most significant water bridges were observed with Gln55, Tyr51 and Gly54 residues accounting for 23, 21 and 13\% respectively of all MD simulation time, indicating the important role of these bindings in the receptorligand interaction.

In cas of the Nutlin-3 exhibited hydrogen bonds with GIn55 and Tyr63 with percentages of 30\% and 3\% respectively. In general, the most required interactions are hydrophobic types formed with lle95, Gln55, Ile57 Val89 and Leu 50 for 57 , 40,34, 29 and 20\%n respectively. Nevertheless as for the compound Pred01 established hydrogen bond, hydrophobic and water bridges interactions with Val89 and His 92 and His 69 for over $30 \%$ and $45 \% 11 \%$ of the simulation time, respectively. Moreover the residue Tyr63 created the most important interaction for $58 \%$.

Figure 11 depicts a temporal representation of interactions and contacts. The top right corner panel shows the total number of interactions established by the protein with the ligand during MD, whereas the top left panel illustrates the residues that interact with the ligand in each route frame. Tyr63, Val89, and His92 are the residues that establish more specific interaction with the ligand Pred01.

\section{Binding free energy calculation using prime molecularmechanics/generalized born surface area (MM-GBSA) approach}

The binding free energy was estimated by Coulomb energy (Coulomb), covalent bond (Covalent), hydrogen bond (Hbond), lipophilic bond (Lipo), п- $\pi$ Packing interaction, the solvent the generalized binding and the binding of Vander Waals (VDW) the values of the contribution of each element on the free energy of total binding between the compounds $\mathrm{N}^{\circ} 04$, Nutlin-3, Pred 01 and the binding pocket of the target protein were has been shown in Table 8.

Table 8

Post simulation of binding free energy for protein-ligand complexes estimated using MM-GBSA analysais

\begin{tabular}{|c|c|c|c|c|c|c|c|c|}
\hline \multirow[t]{2}{*}{ Comp. } & \multicolumn{8}{|c|}{ MMGBSA (kcal/mol) } \\
\hline & $\Delta \mathrm{G}_{\text {Bind }}$ & $\Delta G_{\text {Coulomb }}$ & $\Delta G_{\text {Covalent }}$ & $\Delta G_{\text {Lipo }}$ & $\begin{array}{l}\Delta \mathrm{G}_{\text {Solv }} \\
\mathrm{GB}\end{array}$ & $\Delta G_{v d W}$ & $\begin{array}{l}\Delta G_{H} \\
\text { bond }\end{array}$ & $\begin{array}{l}\Delta G_{\text {Bind }} \\
\text { Packing }\end{array}$ \\
\hline $\begin{array}{l}\text { Compound } \\
\mathrm{N}^{\circ} 04\end{array}$ & -43.461 & 2.831 & 0.983 & -14.568 & 3.082 & -34.878 & -0.127 & -0.782 \\
\hline Nutlin-3 & -71.384 & -9.172 & 3.182 & -27.396 & 19.002 & -55.852 & -0.289 & -0.859 \\
\hline Pred 01 & -60.700 & 0.131 & 2.460 & -20.501 & 5.471 & -46.089 & -0.197 & -1.970 \\
\hline
\end{tabular}


The value of average $\Delta \mathrm{GBind}$ was $-43.46 \mathrm{kcal} / \mathrm{mol}$ for the complex relating to $\mathrm{N}^{\circ} 04,-71.38 \mathrm{kcal} / \mathrm{mol}$ for the complex relating to Nutlin-3 and $-60.70 \mathrm{kcal} / \mathrm{mol}$ for the Pred 01 complex. In general, the newly designed Pred 01 compound and the control compound showed the lowest total binding free energy. Among all interactions, the contributions of Vander Waals energy and lipofil binding were greater than those of other elements with values of $-55.85 \mathrm{kcal} / \mathrm{mol}$ and $-27.39 \mathrm{kcal} / \mathrm{mol}$ for Nutlin-3 and $-46.09 \mathrm{kcal} / \mathrm{mol}$ and $-20,50 \mathrm{kcal} / \mathrm{mol}$ for Pred01 respectively. The Hydrogen bond interaction values for Pred 01 and the most active compound $N^{\circ} 04$ were -0.20 and $-0.13 \mathrm{kcal} / \mathrm{mol}$, respectively, respectively. Which clearly indicated that the newly designed compound formed more stable hydrogen bonds with binding site residues than Compound $\mathrm{N}^{\circ} 04$.

\section{Conclusion}

A database of 29 compounds was used to modulate inhibitory activity against GPX4/MDM2 - p53. The established QSAR model was determined by examining the structure-activity relationship of nitroisoxazole containing spiro [pyrrolidine-oxindole]. The three best models obtained CoMSIA / S+H+A, CoMFA / E+S and HQSAR / B + H with statistically significant indicators giving $R^{2}=0.988 ; Q^{2}=0.560, R^{2}=0.987 ; Q^{2}=0.553$ and $R^{2}=0.796 ; Q^{2}=0.660$ respectively. Based on, the CoMSIA model passed all external validation tests and met the criteria of Tropsha and Globraikh. It was selected to design four new candidates with more potent inhibitory activity than the most active molecule in data set $\mathrm{N}^{\circ} 04$.

In addition, the newly predicted pred01 compounds, $\mathrm{N}^{\circ} 04$ and Nutlin-3 as the control compound were selected for the molecular docking study and the 100 ns MD simulations to analyze the mode of ligand interaction in the binding site of the receptor and assess the stability of the docked complexes respectively. To obtain more information, the binding free energy was examined using the MM-GBSA method. The value of the free energy confirms the stability of the Pred 01 ligand showing the lowest energy. All of these interesting results can be invested in and used to design a nitroisoxazole derivative drug containing spiro [pyrrolidine-oxindole] as more potent inhibitors of GPX4 / MDM2 - p53.

\section{Declarations}

\section{Acknowledgments}

We are grateful to the "Association Marocaine des Chimistes Théoriciens" (AMCT) and "Moroccan Centre of Scientific and Technique research" (CNRST) for their pertinent help concerning the programs.

Funding The authors declare that no funds, grants, or other support were received during the preparation of this manuscript

Competing Interests The authors have no relevant financial or non-financial interests to disclose.

The authors declare that they have no conflict of interest.

Ethical approval This chapter does not contain any studies with human participants or animals performed by any of the authors.

\section{Author information}

\section{Affiliations}

School of Sciences, Moulay Ismail University, Meknes, Morocco 
Kamal Tabti, Larbi Elmchichi, Abdelouahid Sbai, Hamid Maghat \& Tahar Lakhlifi

\section{High School of Technology, Moulay Ismail University, Meknes, Morocco}

Mohammed Bouachrine

\section{Contributions}

Kamal Tabti: Data curation, Writing - original draft; Larbi Elmchichi: Visualization, Investigation; Abdelouahid Sbai: Conceptualization, Methodology, Software; Hamid Maghat: Supervision. Mohammed Bouachrine Software, Validation; Tahar Lakhlifi: Writing - review \& editing. All authors commented on previous versions of the manuscript. All authors read and approved the final manuscript.

\section{Corresponding author}

Abdelouahid Sbai

\section{References}

1. Dixon SJ et al (2012) Ferroptosis: an iron-dependent form of nonapoptotic cell death. Cell 149:1060-1072. https://doi.org/10.1016/j.cell.2012.03.042

2. Yang WS, Stockwell BR (2016) Ferroptosis: death by lipid peroxidation. Trends in cell biology 26:165-176, 2016. https://doi.org/10.1016/j.tcb.2015.10.014

3. Kühn H, Borchert A (2002) Regulation of enzymatic lipid peroxidation: the interplay of peroxidizing and peroxide reducing enzymes. Free Radic Biol Med 33:154-172. https://doi.org/10.1016/S0891-5849(02)00855-9

4. Tarangelo A et al (2018) p53 suppresses metabolic stress-induced ferroptosis in cancer cells. Cell reports 22:569575. https://doi.org/10.1016/j.celrep.2017.12.077

5. Jiang L et al (2015) Ferroptosis as a p53-mediated activity during tumour suppression. Nature 520:57-62. https://doi.org/10.1038/nature14344 https://doi.org/10.1038/nature14344

6. Xie Y et al (2017) The tumor suppressor p53 limits ferroptosis by blocking DPP4 activity. Cell reports 20:16921704. https://doi.org/10.1016/j.celrep.2017.07.055 https://doi.org/10.1038/nature12912

7. Kandoth $\mathrm{C}$ et al (2013) Mutational landscape and significance across 12 major cancer types. Nature 502:333339. https://doi.org/10.1038/nature12634 https://doi.org/10.1038/nature12634

8. Lawrence MS et al (2014) Discovery and saturation analysis of cancer genes across 21 tumour types. Nature 505:495-501. https://doi.org/10.1038/nature12912

9. Kang R, Kroemer G, Tang D (2019) The tumor suppressor protein p53 and the ferroptosis network. Free Radic Biol Med 133:162-168. https://doi.org/10.1016/j.freeradbiomed.2018.05.074

10. Jones SN, Roe AE, Donehower LA, Bradley A (1995) Rescue of embryonic lethality in Mdm2-deficient mice by absence of p53. Nature 378:206-208. https://doi.org/10.1038/378206a0

11. Wang F, Li Y, Ma Z, Wang X, Wang Y (2012) Structural determinants of benzodiazepinedione/peptide-based p53HDM 2 inhibitors using 3D-QSAR, docking and molecular dynamics. J Mol Model 18:295-306.

https://doi.org/10.1007/s00894-011-1041-4

12. Vassilev LT et al (2004) In vivo activation of the p53 pathway by small-molecule antagonists of MDM2. Science 303:844-848. https://doi.org/10.1126/science.1092472 
13. Verma J, Khedkar VM, Coutinho EC (2010) 3D-QSAR in drug design-a review. Current topics in medicinal chemistry 10:95-115. https://doi.org/10.2174/156802610790232260

14. K. TABTI (2020) QSAR Studies of New Compounds Based on Thiazole Derivatives as PIN1 Inhibitors via statistical methods. RHAZES: Green and Applied Chemistry 9:70-91. https://doi.org/10.48419/IMIST.PRSM/rhazesv9.21394

15. Liu S-J et al (2021) Design, synthesis, and biological evaluation of nitroisoxazole-containing spiro [pyrrolidinoxindole] derivatives as novel glutathione peroxidase 4/mouse double minute 2 dual inhibitors that inhibit breast adenocarcinoma cell proliferation. Eur J Med Chem 217:113359. https://doi.org/10.1016/j.ejmech.2021.113359

16. Hagmann WK (2008) The many roles for fluorine in medicinal chemistry. Journal of medicinal chemistry 51:4359-4369. https://doi.org/10.1021/jm800219f

17. Deng $X$ et al (2014) Fluorine modulates species selectivity in the triazolopyrimidine class of Plasmodium falciparum dihydroorotate dehydrogenase inhibitors. Journal of medicinal chemistry 57:5381-5394. https://doi.org/10.1021/jm500481t

18. Muzalevskiy VM, Shastin AV, Balenkova ES, Haufe G, Nenajdenko VG (2009) Synthesis of trifluoromethyl pyrroles and their benzo analogues. Synthesis 2009:3905-3929. https://doi.org/10.1055/s-0029-1217080

19. Huang W-S, Schlinquer C, Poisson T, Pannecoucke X, Charette AB, Jubault P (2018) General Catalytic Enantioselective Access to Monohalomethyl and Trifluoromethyl Cyclopropanes. Chemistry-A European Journal 24:10339-10343. https://doi.org/10.1002/chem.201802685

20. Mei $\mathrm{H}$ et al (2020) Fluorine-containing drugs approved by the FDA in 2019. Chinese Chemical Letters 31:24012413. https://doi.org/10.1016/j.cclet.2020.03.050

21. Mchichi LE et al (2021) In silico design of novel Pyrazole derivatives containing thiourea skeleton as anti-cancer agents using: 3D QSAR, Drug-Likeness studies, ADMET prediction and molecular docking. Materials Today: Proceedings. https://doi.org/10.1016/j.matpr.2021.03.152

22. TABTI K, Sbai A, Maghat H, Bouachrine M, Lakhlifi T (2020) 2D and 3D-QSAR/CoMSIA Comparative Study On a Series of Thiazole Derivatives as SDHI Inhibitors. Maghrebian Journal of Pure Applied Science 6:73-90. https://doi.org/10.48383/IMIST.PRSM/mjpas-v6i2.23108

23. Clark M, Cramer RD III, Van Opdenbosch N (1989) Validation of the general purpose Tripos 5.2 force field. J Comput Chem 10:982-1012. https://doi.org/10.1002/jcc.540100804

24. Sepehri A, Sarrafzadeh M-H (2018) Effect of nitrifiers community on fouling mitigation and nitrification efficiency in a membrane bioreactor. Chemical Engineering Processing-Process Intensification 128:10-18. https://doi.org/10.1016/j.cep.2018.04.006

25. Abdizadeh T et al (2017) Design, synthesis and biological evaluation of novel coumarin-based benzamides as potent histone deacetylase inhibitors and anticancer agents. Eur J Med Chem 132:42-62. https://doi.org/10.1016/j.ejmech.2017.03.024

26. Pourbasheer E, Bazl R, Amanlou M (2014) Molecular docking and 3D-QSAR studies on the MAPKAP-K2 inhibitors. Med Chem Res 23:2252-2263. https://doi.org/10.1007/s00044-013-0820-0

27. Cramer RD, Wendt B (2014) Template CoMFA: The 3D-QSAR Grail. J Chem Inf Model 54:660-671. https://doi.org/10.1021/ci400696v

28. Gomes VM, Fernandes AM, Faia A, Melo-Pinto P (2017) Comparison of different approaches for the prediction of sugar content in new vintages of whole Port wine grape berries using hyperspectral imaging. Computers electronics in agriculture 140:244-254. https://doi.org/10.1016/j.compag.2017.06.009 
29. Golbraikh A, Tropsha A (2002) Beware of q2! Journal of molecular graphics modelling 20:269-276. https://doi.org/10.1016/S1093-3263(01)00123-1

30. Hailey DW et al (2010) Mitochondria supply membranes for autophagosome biogenesis during starvation. Cell 14:656-667. https://doi.org/10.1016/j.cell.2010.04.009

31. Pratim Roy P, Paul S, Mitra I, Roy K (2009) On two novel parameters for validation of predictive QSAR models. Molecules 14:1660-1701. https://doi.org/10.3390/molecules14051660

32. Namasivayam V, Günther R (2007) PSO@ AUTODOCK: A fast flexible molecular docking program based on swarm intelligence. Chem Biol Drug Des 70:475-484. https://doi.org/10.1111/j.1747-0285.2007.00588.x

33. TABTI K, EIMCHICHI L, Abdelouahid S, MAGHAT H, BOUACHRINE M, and T. LAKHLIFI (2021) In silico design of novel PIN1 inhibitors by combined of 3D-QSAR, molecular docking, molecular dynamic simulation and ADMET studies. J Mol Struct 1253:132291. https://doi.org/10.1016/j.molstruc.2021.132291

34. Bowers KJ et al (2006) Scalable algorithms for molecular dynamics simulations on commodity clusters 2006 : 43-43. https://doi.org/10.1109/SC.2006.54

35. Evans DJ, Holian BL (1985) The nose-hoover thermostat. J Chem Phys 83:4069-4074. https://doi.org/10.1063/1.449071

36. Théry C et al (2018) Minimal information for studies of extracellular vesicles 2018 (MISEV2018): a position statement of the International Society for Extracellular Vesicles and update of the MISEV2014 guidelines. Journal of extracellular vesicles 7:1535750. https://doi.org/10.1080/20013078.2018.1535750

37. Patel J, Woolley J (2020) Necrotizing periodontal disease: Oral manifestation of COVID-19. Oral Dis. https://doi.org/10.1111/odi.13462

38. Bhowmick GD et al (2020) Coronavirus disease 2019 (COVID-19) outbreak: some serious consequences with urban and rural water cycle. NPJ Clean Water 3:1-8. https://doi.org/10.1038/s41545-020-0079-1

39. Veber DF, Johnson SR, Cheng H-Y, Smith BR, Ward KW, Kopple KD (2002) Molecular properties that influence the oral bioavailability of drug candidates. Journal of medicinal chemistry45:2615-2623.

https://doi.org/10.1021/jm020017n

40. Remko M, Swart M, Bickelhaupt FM (2006) Theoretical study of structure, pKa, lipophilicity, solubility, absorption, and polar surface area of some centrally acting antihypertensives. Bioorg Med Chem 14:1715-1728.

https://doi.org/10.1016/j.bmc.2005.10.020

41. Bringmann G, Rummey C (2003) 3D QSAR investigations on antimalarial naphthylisoquinoline alkaloids by comparative molecular similarity indices analysis (CoMSIA), based on different alignment approaches. J Chem Inf Comput Sci 43:304-316. https://doi.org/10.1021/ci025570shttps://doi.org/10.1021/ci025570s

42. Monge $A$ (2006) Création et utilisation de chimiothèques optimisées pour la recherche «in silico» de nouveaux composés bioactifs. Université d’Orléans

\section{Figures}

\section{Figure 1}

(a) Nutlin-3 / (b) BDP (benzodiazépinediones) structures 

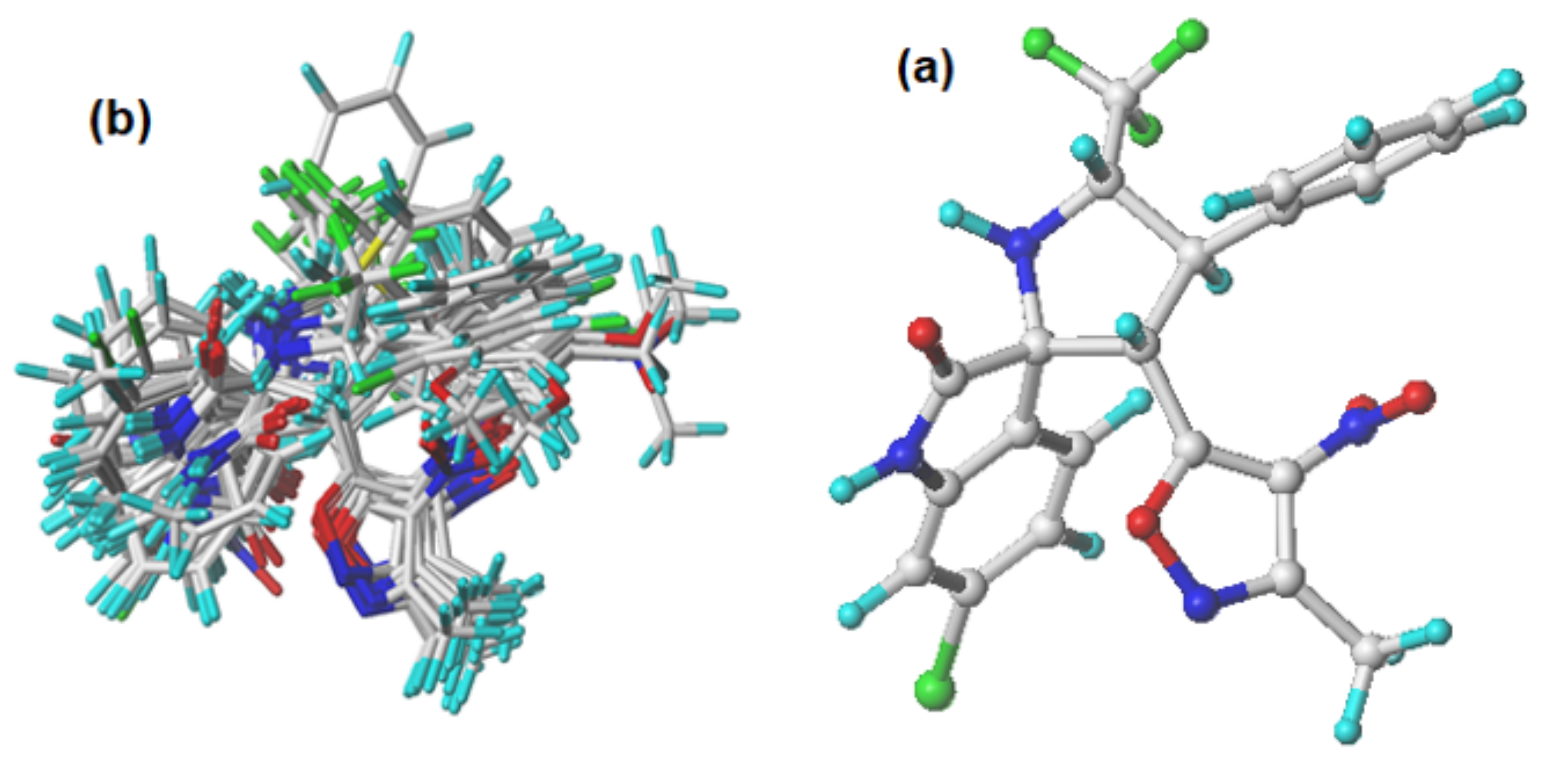

Figure 2

Molecular alignment, (a) most active compound $\mathrm{N}^{\circ} 04$ among the data set (b) 3D-QSAR structure aligned compounds of the training set
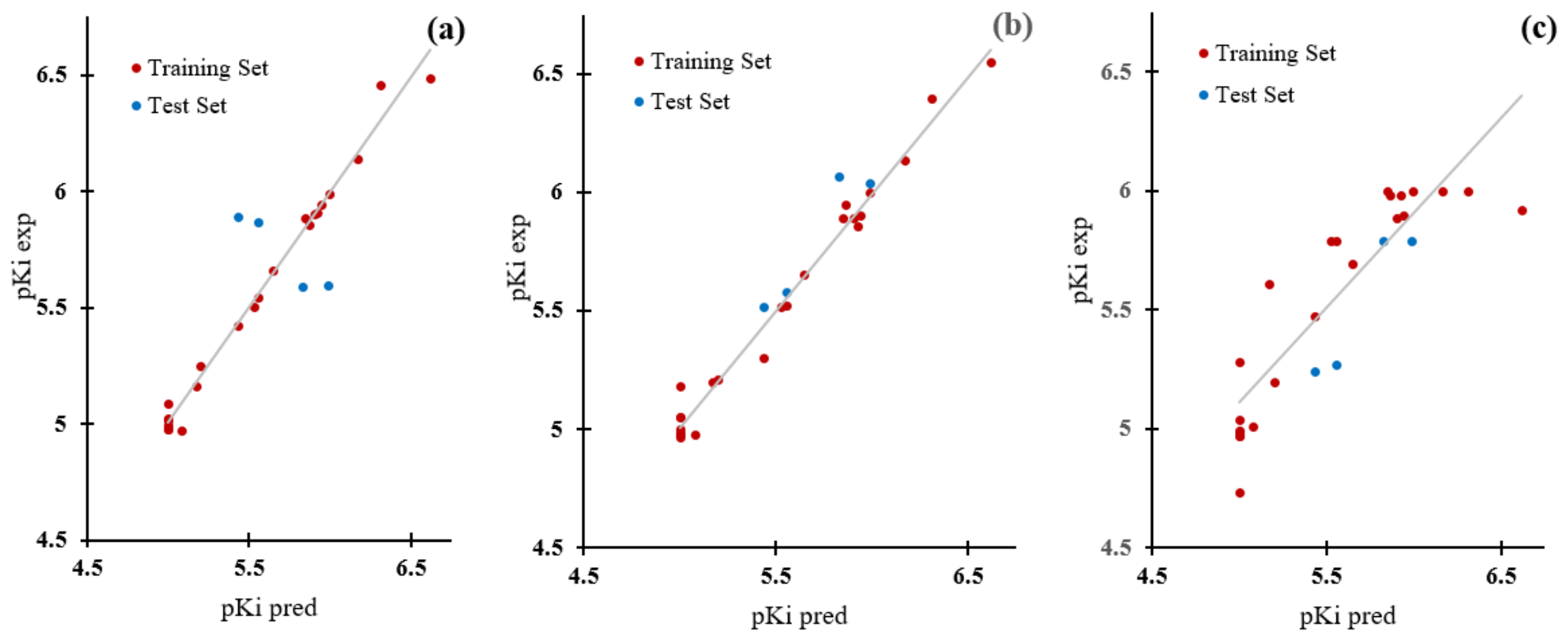

Figure 3

Graphs of experimental pKi values vs predicted pKi values by the CoMFA (a), CoMSIA (b) and HQSAR models 

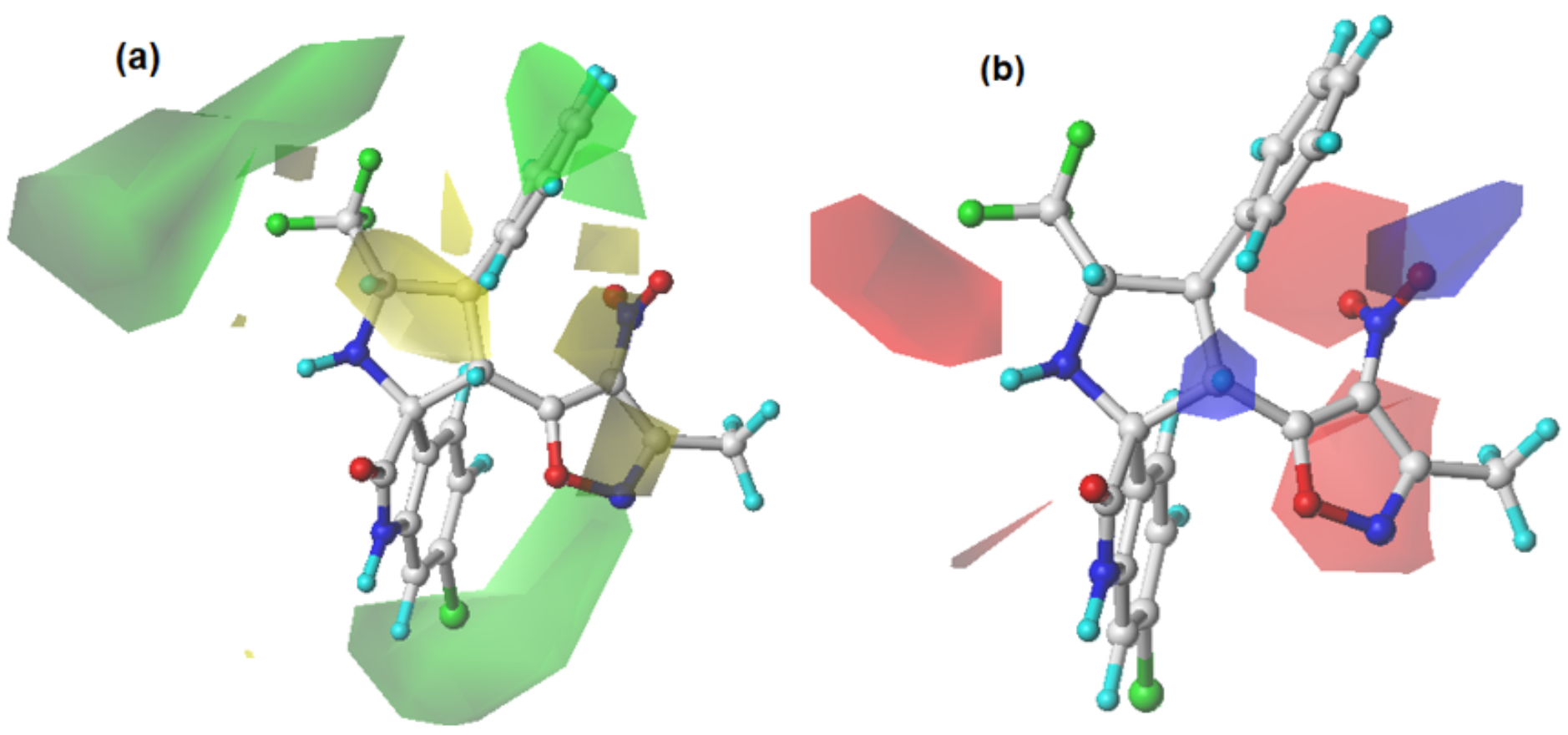

Figure 4

Contour map of CoMFA analysis (a) Steric, (b) electrostatic in combination with compound $\mathrm{N}^{\circ} 04$
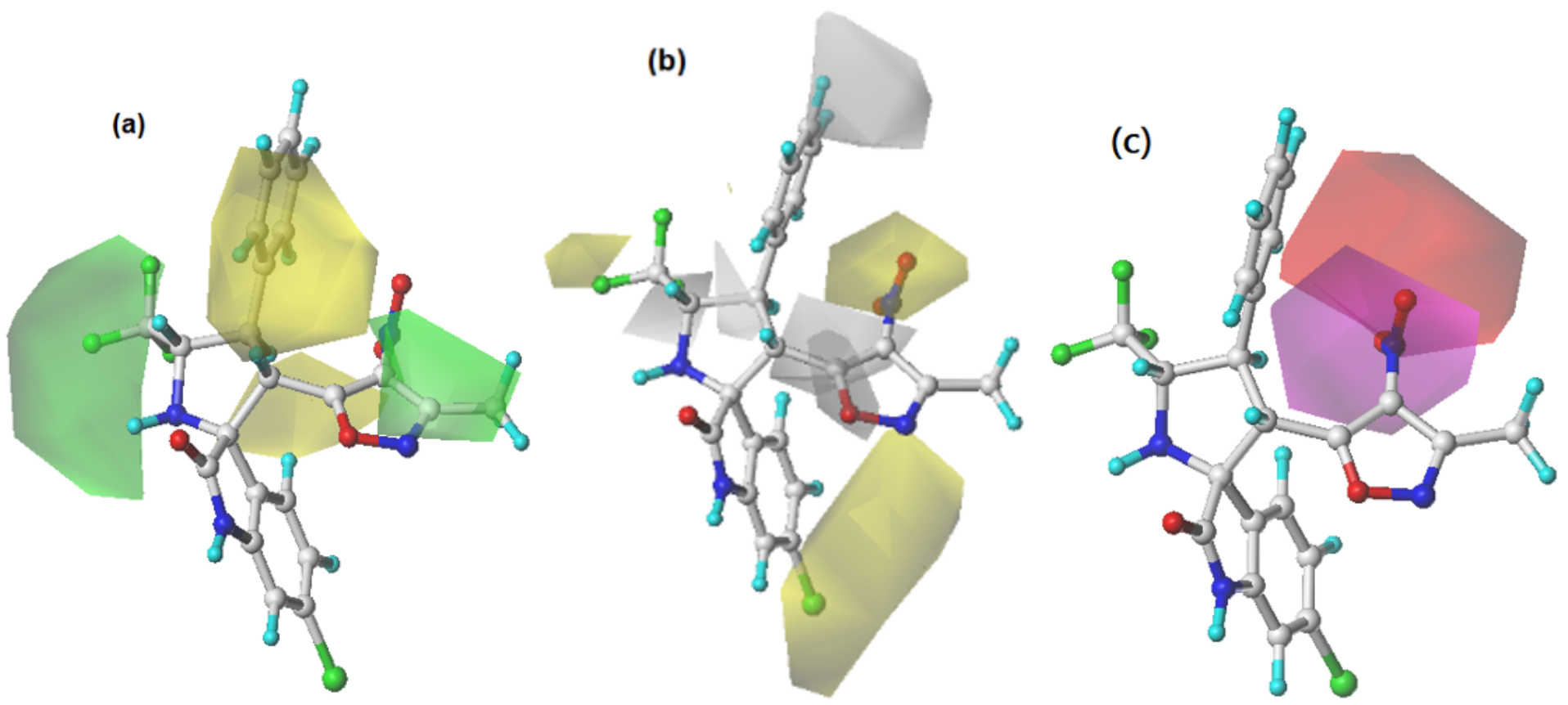

Figure 5

Contour map of CoMSIA analysis (a) Steric, (b) hydrophobic, and (c) hydrogen bond acceptor in combination with compound $\mathrm{N}^{\circ} 04$ 


\section{Figure 6}

Hologram quantitative structure activity relationship model contribution map of (a) the most compound $\mathrm{N}^{\circ} \mathrm{O} 4$ and (b) the least compound $\mathrm{N}^{\circ} 20$

\section{Figure 7}

$2 \mathrm{D}$ visualization showing interactions of new designed compound, compound $\mathrm{N}^{\circ} 04$ and Nutlin-3

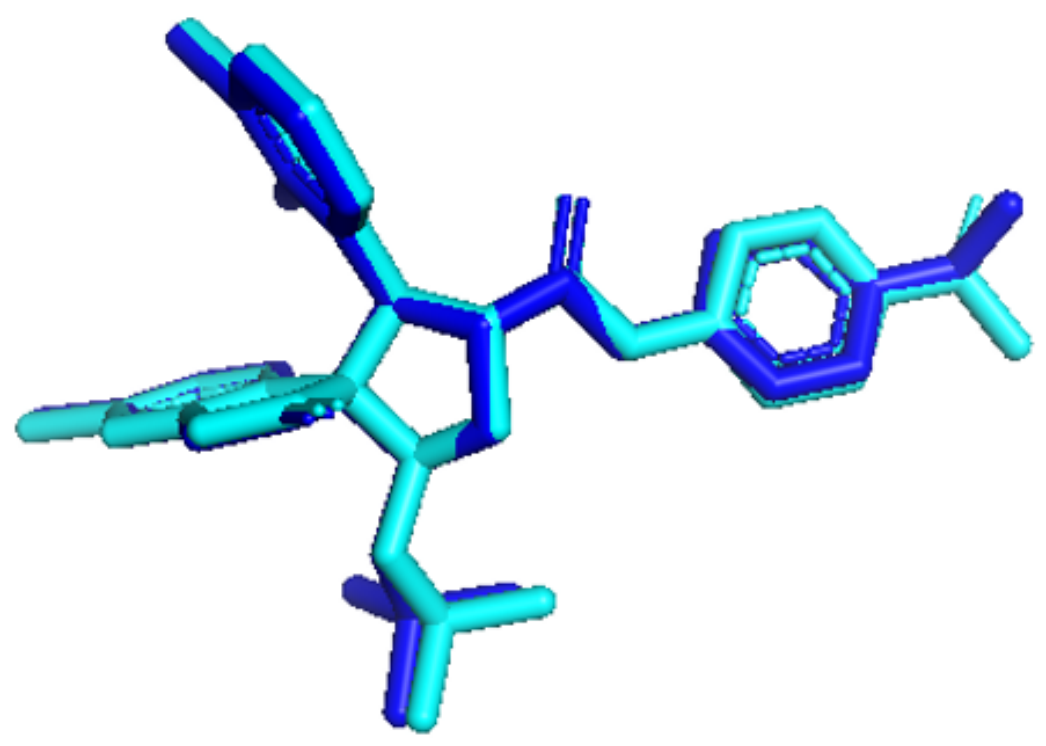

\section{Figure 8}

Re-docking pose with an RMSD value of $0,87 \AA$ (cyan= native ligand, blue = docked ligand)

\section{Figure 9}

RMSD of (a) N04/receptor, (b) Nutlin-3/receptor and (c) Pred 01/receptor

\section{Figure 10}

RMSF of compound (a) N04/receptor, (b) Nutlin-3/receptor and (c) Pred 01/receptor. 


\section{Figure 11}

Histoframe showing the protein/ligand interaction and A timeline representation of the interactions and contacts of three compounds, (a) compound N04, (b) Nutlin-3 and (c) Pred01 throughout the simulation time of 100 ns.

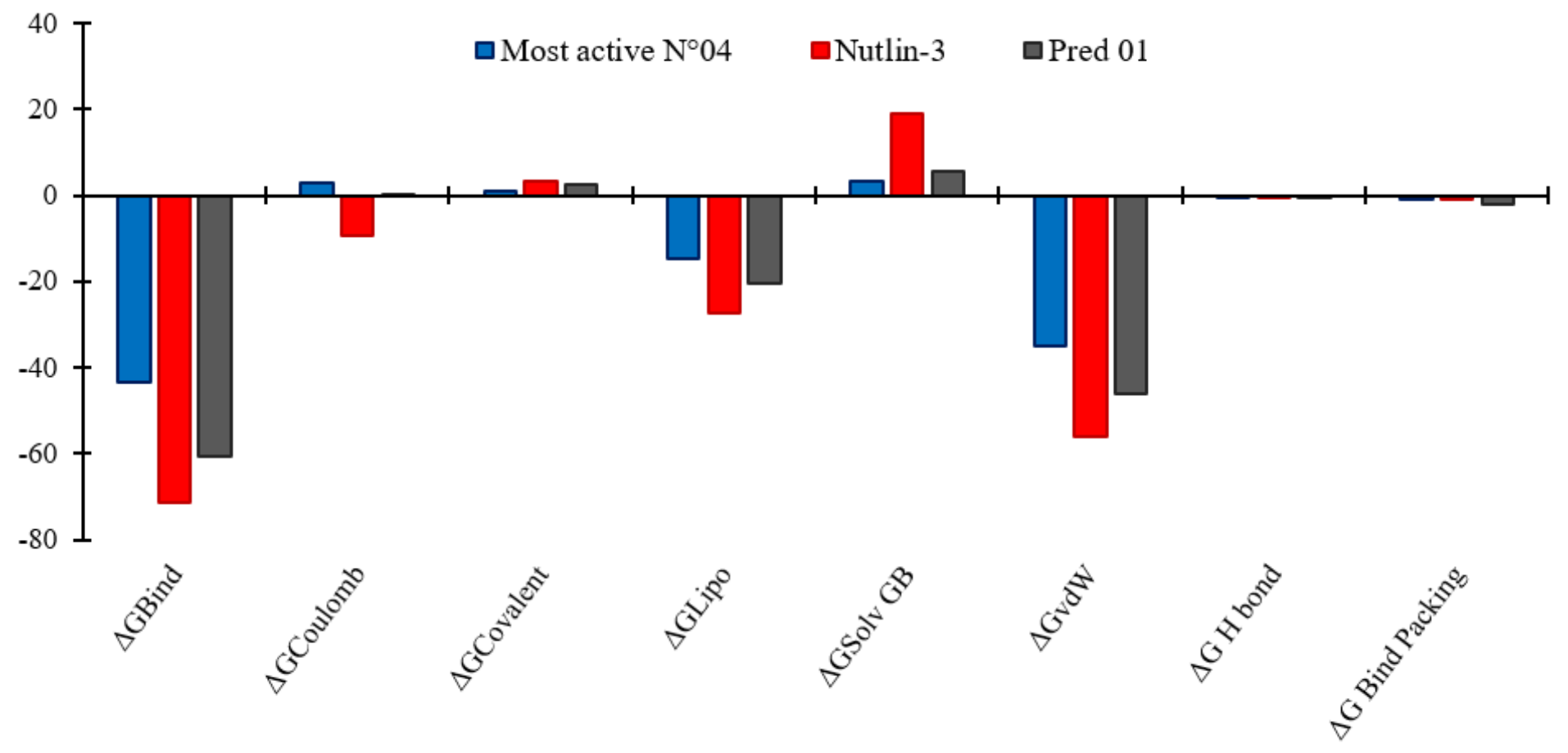

Figure 12

Free energy binding of the studied complexes 